\title{
Simplicity, flexibility, and respect: preferences related to patient education in hardly reached people with type 2 diabetes
}

This article was published in the following Dove Press journal:

Patient Preference and Adherence

5 November 2015

Number of times this article has been viewed

\author{
Rikke Torenholt ${ }^{1}$ \\ Annemarie Varming' \\ Gitte Engelund' \\ Susanne Vestergaard ${ }^{2}$ \\ Birgitte Lund Møller ${ }^{3}$ \\ Regitze Anne Saurbrey Pals' \\ Ingrid Willaing' \\ 'Health Promotion Research, Steno \\ Diabetes Center A/S, Gentofte, \\ ${ }^{2}$ Danish Diabetes Association, \\ Copenhagen, ${ }^{3}$ Region of Southern \\ Denmark, Vejle, Denmark
}

\begin{abstract}
Individuals with lower income and less education are two to four times more likely to develop diabetes than more advantaged individuals. In response to this, there is a need for developing health promotion activities targeting hardly reached populations. The aim of this study was to examine the perspectives of hardly reached people with type 2 diabetes on patient education, focusing on their wishes and needs regarding format and approach. Data were collected through qualitative interviews with nine individuals with type 2 diabetes with little or no education and characterized as hardly reached patients by health professionals. Interviews were transcribed verbatim and analyzed according to systematic text condensation. We identified four main categories of preferences for patient education: 1) flexibility related to start time, duration, and intensity; 2) simple and concrete education tools, with regard to design and extent; 3 ) being together, related to meeting people in a similar situation; and 4) respectful educators, related to constructive patient-educator relationships. Insights into the preferences of hardly reached people with diabetes can contribute to the development of appropriately tailored patient education for this patient group.
\end{abstract}

Keywords: patient education, type 2 diabetes, hardly reached people, preferences

\section{Introduction}

Social factors such as income and education play a key role in the development and progression of type 2 diabetes. ${ }^{1-4}$ Individuals with lower income and less education are two to four times more likely to develop diabetes than more advantaged individuals. ${ }^{1}$ Moreover, lower income and less education are important determinants of the mortality risk associated with type 2 diabetes. ${ }^{5}$

Structured self-management education is widely recognized as an important cornerstone in the management of type 2 diabetes; successful diabetes management requires sustained behavior change and the necessary skills to handle everyday life with diabetes. ${ }^{6}$ Hence, it is critical that all people with type 2 diabetes, including those in high-risk groups, are offered structured self-management education. However, targeting people with low income and low education poses a considerable challenge; they attend patient education programs less frequently and may be labeled as "hard-to-reach" or "hardly reached". ${ }^{7}$ Fisher et al emphasize that individuals frequently characterized as hard-to-reach are better described as hardly reached; the problem lies not in their personal characteristics but in the frequent failure of interventions to engage them. ${ }^{8}$ Thus, an important consideration is whether patient education adequately corresponds to the wishes and needs of hardly reached people with type 2 diabetes or whether changes in
Correspondence: Regitze Anne Saurbrey Pals

Steno Diabetes Center A/S, Niels Steensens Vej 8, 2820 Gentofte,

Denmark

Tel +4530794195

Email riap@steno.dk 
format and approach are needed. In this study, hardly reached people were defined as individuals with low or no education and job status outside the labor market.

We examined the perspectives of hardly reached people with type 2 diabetes on patient education, focusing on their wishes and needs regarding format and approach.

\section{Methods}

We conducted interviews with nine individuals with type 2 diabetes (Table 1). Participants were recruited from three patient education centers in Denmark (two municipality based and one hospital based). Known patient educators assisted us using a purposive sampling strategy. ${ }^{9}$ Potential subjects were identified by patient educators on the basis that they had previously taken part in existing patient education courses on offer at the respective patient education centers without, apparently, obtaining any measurable benefit from their participation. This included people who educators experienced to be difficult to engage in education sessions or who did not participate due to complex life conditions. Additional sampling criteria included low or no education and job status outside the labor market (eg, retired or on disability pension). We experienced significant difficulty in recruiting participants due to their cancellations of scheduled interviews and late arrivals for the interviews. Thus, the recruitment process was time consuming and challenging and resulted in a smaller number of participants than intended. Two authors (RT and GE) conducted interviews in
Danish lasting 120-180 minutes each. Five participants were interviewed in their homes and four at different patient education centers. The long duration of the interviews reflects the fact that a considerable amount of time was required to adapt the conversation to the premises and narratives of participants. Furthermore, the participants were introduced to six education tools drawing on different perceptual elements (auditory, visual, tactual, and kinesthetic), inspired by the learning styles introduced by Dunn and Dunn. ${ }^{10}$ This included three education tools from two existing patient education concepts ${ }^{11,12}$ and three newly developed tools to explore patients' experiences and challenges related to living with diabetes. Tools from the existing patient education concepts are structured around elements such as images, quotations, and statements. The newly developed tools specifically address tactile and kinesthetic learning through, eg, physical involvement and samples of food items. The use of these tools successfully facilitated interaction in the interviews. A standard informed consent was obtained from all participants assuring anonymity and confidentiality; participants received a copy of the consent form.

A semistructured interview guide addressed the following three main themes: 1) experience with patient education (focusing on format and approach); 2) experience with other learning situations and everyday life with diabetes; and $3)$ preferences for various education tools representing different learning styles. The third theme was addressed by the use of the aforementioned education tools. The introduction of

Table I Participant characteristics

\begin{tabular}{|c|c|c|c|c|c|c|c|}
\hline Participant & Age & Sex & $\begin{array}{l}\text { Diabetes } \\
\text { duration } \\
\text { (years) }\end{array}$ & $\begin{array}{l}\text { Employment } \\
\text { status }\end{array}$ & Comorbidities & Occupation & $\begin{array}{l}\text { Cohabitation } \\
\text { status }\end{array}$ \\
\hline I & 37 & Male & 2 & Unemployed & $\begin{array}{l}\text { Back and knee } \\
\text { problems and dyslexia }\end{array}$ & $\begin{array}{l}\text { Health care } \\
\text { assistant }\end{array}$ & $\begin{array}{l}\text { Living with } \\
\text { brother }\end{array}$ \\
\hline 2 & 73 & Female & 10 & Retired & $\begin{array}{l}\text { Heart problems, } \\
\text { dermatitis, and } \\
\text { memory difficulties }\end{array}$ & Secretary & Living alone \\
\hline 3 & 74 & Male & $\mathrm{N} / \mathrm{A}$ & Retired & $\begin{array}{l}\text { Memory and learning } \\
\text { difficulties }\end{array}$ & Bricklayer & $\begin{array}{l}\text { Divorced and } \\
\text { living alone }\end{array}$ \\
\hline 4 & 49 & Female & $\mathrm{N} / \mathrm{A}$ & $\begin{array}{l}\text { Disability } \\
\text { pensioner }\end{array}$ & $\begin{array}{l}\text { Depression, mild } \\
\text { brain injury, asthma, } \\
\text { and dyslexia }\end{array}$ & None & Living alone \\
\hline 5 & 43 & Female & I & $\begin{array}{l}\text { Disability } \\
\text { pensioner }\end{array}$ & ADHD & None & Living alone \\
\hline 6 & 52 & Male & 2 & $\begin{array}{l}\text { Disability } \\
\text { pensioner }\end{array}$ & Arthritis and dyslexia & Shoemaker & $\begin{array}{l}\text { Divorced and } \\
\text { living alone }\end{array}$ \\
\hline 7 & 72 & Male & $3-4$ & Retired & $\begin{array}{l}\text { Heart problems and } \\
\text { high cholesterol }\end{array}$ & None & $\begin{array}{l}\text { Living with } \\
\text { wife }\end{array}$ \\
\hline 8 & 41 & Male & I & Re-training & None & None & Living alone \\
\hline 9 & 66 & Female & 20 & Retired & Arthritis & None & $\begin{array}{l}\text { Living with } \\
\text { husband }\end{array}$ \\
\hline
\end{tabular}


these tools implied that participants were provided with a brief explanation of the tool, its intended function, and an example of how it could be applied in an education situation.

Interviews were video recorded and transcribed verbatim in Danish. Data were analyzed by RT and GE using systematic text condensation, ${ }^{13}$ which consisted of 1 ) reading all the material to get an overall impression and identify preliminary themes; 2) identifying, classifying, and sorting meaning units related to previously identified themes and labeling code groups; 3) systematic abstraction of meaning units within the thematic codes; and 4) reconceptualization of data and development of concepts and descriptions. Throughout the analysis, our focus was to identify recurring wishes and needs related to the format and approach of patient education.

\section{Results}

Participants (five men and four women, age 37-74) reported various health problems and difficulties besides diabetes (Table 1).

Participants articulated various perspectives. Four broad categories represented different aspects of wishes and needs related to the format and approach of patient education (Figure 1).

\section{Flexibility}

Participants wished for flexibility in terms of overall planning and scheduling and the duration and intensity of a given educational situation. A flexible start time was mentioned as important. The majority of participants reported that their circadian rhythm was incompatible with regular working hours in the health care service. In addition, some participants reported regularly being late for appointments and having trouble getting up and around, which necessitates a flexible format. Thus, educators should be able to adjust the intensity and duration of patient education to the given situation. Participants reported that flexibility was particularly important in situations where participants cannot maintain focus or if unexpected interruptions occur, such as spontaneous breaks or people arriving very late.

\section{Simple and concrete education tools}

This category is related to both the complexity and extent of education tools and the perceptual elements they contain. Participants requested easy-to-understand education and education tools with a very clear purpose and little introduction. The need for simplicity was also observed during the interviews. When introducing an education tool containing

\section{Flexibility}

"I get up late. It varies between 10 and 12. I usually walk my dog around 12 PM (...). I usually go to bed between $12 \mathrm{AM}$ and five in the morning" (1)

"I am never ever on time. I am always too late. It is unbelievable that my employer used to put up with it" (2).

"When I got home afterwards I was very tired. I could lie on the couch or go to bed or fall asleep immediately. I would like if we didn't do as much some of the time. If we had more education sessions spread over a longer period. It was just too much. Too intense" (4)

\section{Respectful educators}

"I got the impression that he [educator] thought I was stupid. That I do not like." (2)

"I would like to be able to show my doctor that I understand what I have been told. I feel a little stupid (...). I really don't want to be called stupid, and yet it is stupid that I do not do anything" (9)

"They [educators] have no humor. They take themselves too serious. I mean, it [patient education] is so serious. I would prefer education with a little more humor in it" (6) 


\title{
Simple and concrete education tools
}

"I cannot figure it out [the education tool]. What it means and how to use it. It is not interesting. I cannot explain why (...). I would not call it simple, and I cannot see how I can use it" (3)

"It is quite difficult for the brain with a lot of inputs (...). A bomb sets off if you get too many [inputs]. It is actually very difficult, it depends on how you feel." (8)

"The words start blurring and then I lose my concentration. Then I will just leave it [marking with his hands that he will put the text aside]." (1)

"I like these ones better [big pictures (a4)] because they are easier to hold on to and they have nice colors compared to smaller ones. I think it is easier to relate to." (4)

"I think it [education tool] is funny. It's much better than posters (...). You can take it up and look at it just because it's fun and it's rubber right? I definitely think this will help the understanding." (2)

"I feel quite unpleasant actually [when moving further towards the other end of a big scale placed on the floor]. I do. Because I know it involves some ugly things. It feels much better to be up here. It's a little unhealthy in the other end." (4)

"We had those folders with diabetes [written information material about diabetes], but you forget about that" (7)

\section{Being together}

\begin{abstract}
"The best thing [about patient education] is that you get out there and practice a little. And that you do it together with others. That you are not alone at the bottom." (1)

"It [patient education] gave me so much it cannot be described (...). It is good that I am not alone in the world. There are seven others, and many more." (2)

"Not too many [people] at the same time because I am not used to that. When I went to school we were only six and I think we were 25 [attending patient education]. So it is very crowded if you want a chance to digest everything. I am not that type (...). I have never liked big crowds. If I do not feel safe and secure, I do not say anything." (5)
\end{abstract}

Figure I Selected citations representing patient preferences.

many choices, some participants appeared over stimulated, becoming excessively talkative, and others became passive. Most participants reported being dyslexic and were uncomfortable being asked to read or write. Participants' perceptual preferences were assessed through their own words and through their responses to different education tools presented during interviews. They stated and exhibited a clear preference for education tools drawing on tactile and kinesthetic elements, such as "hands-on" learning or experimental learning, including physical involvement. ${ }^{14}$ Participants responded very positively to education tools requiring light physical activity. They seemed to prefer larger educational materials and those they could touch and feel.

\section{Being together}

Participants clearly expressed a desire to meet others in similar situations. Group-based education seemed very attractive. However, several participants also expressed the view that too many other participants could create insecurity and reticence. Compared to the usual format of 12-15 participants in group-based patient education, the interviewees found that six or seven people would be an optimal group size. 


\section{Respectful educators}

Most participants described very negative experiences in previous contacts with health care professionals and others employed in the health and social services sector. These experiences significantly affected their views on educators. Negative experiences primarily related to participants' feelings of being treated disrespectfully. Therefore, they requested more respectful educators. However, participants also viewed health care professionals as authority figures, which contributed to their experiences of very unequal relationships.

\section{Discussion}

This study sheds light on four practical elements related to patient education targeting hardly reached people with type 2 diabetes. Strengths of this study include interviews that were geographically dispersed and represented both sexes. We conducted in-depth interviews based on a semistructured guide, and all participants provided full interviews.

Limitations include the sample size and strategy. Originally, we intended to include more participants in the study. However, the recruitment process was extremely challenging and time consuming. We found that we reached saturation in relation to the main topics according to the criteria for saturation as defined by Crouch and McKenzie ${ }^{15}$ and Bowen. ${ }^{16}$ To address the issue of saturation, we conducted in-depth interviews for at least 120 minutes each and analyzed data using a validated model that relied on continuous monitoring of interview material in relation to conceptualization of data. Altogether, saturation was reached for all four main categories: flexibility, simple and concrete education tools, being together, and respectful educators.

We sought participants who are hard to identify and to maintain contact with, which includes frequent difficulty in keeping appointments. Thus, the purposive sampling represents hardly reached people with type 2 diabetes who were known to a patient educator. It is possible that a different sampling strategy and study population would yield different findings. For instance, it is likely that patients with no prior experience with patient education differ from patients having received some kind of patient education.

Although we interviewed people with diabetes, our results may be transferable to people with other chronic diseases. Our findings correspond to studies among other hardly reached groups, such as ethnic minorities, low-income people, and people with limited literacy skills. ${ }^{17-19}$ A study examined barriers and facilitators to accessing social services for hardly reached groups from a voluntary and community sector perspective. ${ }^{20}$ The study describes a number of perceived barriers that correspond to findings in our study including participants' previous negative experiences with the health care and social services, including factors such as poor location and opening hours. The study suggests that offering flexible services, respectful treatment, and establishing trust can improve access. The study further concludes that outreach services may be relevant to this target group. ${ }^{20}$

Findings related to the challenges of attending patient education also concern the general population of people with diabetes. ${ }^{21}$ Addressing this issue may therefore not only benefit the hardly reached but also the general population being offered patient education for people with diabetes.

The preferences of hardly reached people with diabetes may be related to a low level of health literacy in this group. Previous studies have demonstrated that low income and low education are associated with poor health literacy among people with diabetes. ${ }^{22,23}$ Future studies of preferences of hardly reached people with diabetes may benefit from drawing on the field of health literacy.

Insights into the education preferences of hardly reached people with diabetes may contribute to the development of appropriately tailored patient education targeting this group of people. All study findings point to very concrete elements of patient education that are suitable and obtainable first steps to improvement, such as offering flexible start times and smaller groups. In addition, participants reported substantial emotional barriers toward health care professionals, which clearly indicated a need for clarifying roles and expectations to build new positive and constructive relationships and avoid further disappointment. In light of this finding, it requires significant education skills as well as empathy to accommodate such personal stories in group-based education sessions.

Furthermore, our findings may inform the development of tailored education tools emphasizing tactile and kinesthetic elements to stimulate learning through physical involvement. Hartman et al reported that individuals with limited literacy skills preferred practical hands-on activities in nutrition education. The authors further suggest that learning through games may be of value to this group. ${ }^{17}$ However, more insights about the wishes and needs of hardly reached people with type 2 diabetes are needed, relating to the content and format of patient education as well as the development and testing of education programs and tools.

\section{Acknowledgments}

We thank Susanne Mittag and Sabrina Jensen for transcribing interviews and providing useful comments. We also thank 
the participants for agreeing to be interviewed and for their valuable contribution to this research. This work was supported by the Danish Ministry of Health.

\section{Disclosure}

RT, AV, RASP, and IW are employed by Steno Diabetes Center A/S, a research hospital working in the Danish National Health Service and owned by Novo Nordisk A/S. GE was at the time of investigation employed by Steno Diabetes Center A/S, a research hospital working in the Danish National Health Service and owned by Novo Nordisk A/S. SV is employed by the Danish Diabetes Association, an NGO independent of commercial interests and views. BLM is employed by Region of Southern Denmark, which is one of the five administrative units in Denmark. Region of Southern Denmark relies entirely on central state funding and funding from the municipalities and pursues no commercial interests. The authors report no other conflicts of interest in this work.

\section{References}

1. Hill J, Nielsen M, Fox MH. Understanding the social factors that contribute to diabetes: a means to informing health care and social policies for the chronically ill. Perm J. 2013;17(2):67-72.

2. Agardh E, Allebeck P, Hallqvist J, Moradi T, Sidorchuk A. Type 2 diabetes incidence and socio-economic position: a systematic review and meta-analysis. Int J Epidemiol. 2011;40(3):804-818.

3. Chaufan C, Weitz R. The elephant in the room: the invisibility of poverty in research on type 2 diabetes. Humanity Soc. 2009;33(1):74-98.

4. Brown AF, Ettner SL, Piette J, et al. Socioeconomic position and health among persons with diabetes mellitus: a conceptual framework and review of the literature. Epidemiol Rev. 2004;26(1):63-77.

5. Saydah S, Lochner K. Socioeconomic status and risk of diabetes-related mortality in the U.S. Public Health Rep. 2010;125(3):377-388.

6. Jarvis J, Skinner TC, Carey ME, Davies MJ. How can structured selfmanagement patient education improve outcomes in people with type 2 diabetes? Diabetes Obes Metab. 2010;12(1):12-19.

7. Freimuth VS, Mettger W. Is there a hard-to-reach audience? Public Health Rep. 1990;105(3):232-238.

8. Fisher EB, Coufal MM, Parada H, et al. Peer support in health care and prevention: cultural, organizational, and dissemination issues. Аппи Rev Publ Health. 2014;35:363-383.
9. Marshall MN. Sampling for qualitative research. Family Pract. 1996; 13(6):522-525.

10. Dunn R, Griggs SA, Gorman BS, Olson J, Beasley MA. Meta-analytic validation of the Dunn and Dunn model of learning-style preferences. J Educ Res. 1995;88(6):353-362.

11. Toolbox forgroup based patienteducation [website on the Internet]. Gentofte: Steno Diabetes Center; c2015 [updated November 7, 2014; cited June 2, 2015]. Available from: https://steno.dk/en/pages/sundhedsprofessionelle/ needpages/den_sundhedspaedagogiske_vaerktoejskasse.aspx. Accessed June 29, 2015.

12. Download dialogue tools from EMMA [website on the Internet]. Gentofte: Steno Diabetes Center; c2015 [updated November 19, 2014; cited June 2, 2015]. Available from: https://steno.dk/en/pages/ sundhedsprofessionelle/pages/download_dialogvaerktoj_emma.aspx. Accessed June 29, 2015.

13. Malterud K. Systematic text condensation: a strategy for qualitative analysis. Scand J Public Health. 2012;40(8):795-805.

14. Reid JM. The learning style preferences of ESL students. Tesol Quart. 1987;21:87-110.

15. Crouch M, McKenzie H. The logic of small samples in interview-based qualitative research. Soc Sci Inform. 2006;45(4):483-499.

16. Bowen GA. Naturalistic inquiry and the saturation concept: a research note. Qual Res. 2008;8(1):137-152.

17. Hartman TJ, McCarthy PR, Park RJ, Schuster E, Kushi LH. Focus group responses of potential participants in a nutrition education program for individuals with limited literacy skills. J Am Diet Assoc. 1994;94(7): 744-748.

18. Jones M, Hepburn S, Man J, Ridout J, Gable D. A community outreach service for vulnerable people with diabetes. Diabetes Prim Care. 2011; 13(2):111-116.

19. Thom DH, Ghorob A, Hessler D, De Vore D, Chen E, Bodenheimer TA. Impact of peer health coaching on glycemic control in low-income patients with diabetes: a randomized controlled trial. Ann Fam Med. 2013;11(2):137-144.

20. Flanagan SM, Hancock B. 'Reaching the hard to reach'-lessons learned from the VCS (voluntary and community Sector). A qualitative study. BMC Health Serv Res. 2010;10:92.

21. Graziani C, Rosenthal MP, Diamond JJ. Diabetes education program use and patient-perceived barriers to attendance. Fam Med. 1999;31(5): 358-363.

22. Kim S, Love F, Quistberg DA, Shea JA. Association of health literacy with self-management behavior in patients with diabetes. Diabetes Care. 2004;27(12):2980-2982.

23. Schillinger D, Grumbach K, Piette J, et al. Association of health literacy with diabetes outcomes. JAMA. 2002;288(4):475-482.
Patient Preference and Adherence

\section{Publish your work in this journal}

Patient Preference and Adherence is an international, peer-reviewed, open access journal that focuses on the growing importance of patient preference and adherence throughout the therapeutic continuum. Patient satisfaction, acceptability, quality of life, compliance, persistence and their role in developing new therapeutic modalities and compounds to optimize

\section{Dovepress}

clinical outcomes for existing disease states are major areas of interest for the journal. This journal has been accepted for indexing on PubMed Central. The manuscript management system is completely online and includes a very quick and fair peer-review system, which is all easy to use. Visit http://www. dovepress.com/testimonials.php to read real quotes from published authors. 